Article

\title{
Water Pool Behaviors of Water Lubricating for Glass/Steel Point Contact
}

\author{
Hang Zhang ${ }^{1,2}$, Shu-Hai Liu ${ }^{1,2, *}$ and Hua-Ping Xiao ${ }^{1,2}$ \\ 1 College of Mechanical and Transportation Engineering, China University of Petroleum-Beijing, \\ Beijing 102249, China; zhanghang@cup.edu.cn (H.Z.); hxiao@cup.edu.cn (H.-P.X.) \\ 2 Laboratory of Tribology and Surface Engineering, China University of Petroleum-Beijing, \\ Beijing 102249, China \\ * Correspondence: Liu_shu_hai@163.com; Tel.: +86-010-8973-3762
}

Received: 17 July 2017; Accepted: 1 September 2017; Published: 3 September 2017

\begin{abstract}
The behavior of pools of water for lubrication under a point of contact between a glass disk and a steel ball is studied here, employing a home-built apparatus. A deformed water pool is found to form around the contact region under different rolling speeds. To investigate the effect of rolling speed on the water pool, two parameters (advancing angle and receding angle) are introduced to describe the shape of the water pool. Two distinct glass surfaces, namely a smooth surface and a microgrooved surface, are observed. In the case of the smooth surface, the advancing/receding angle of the water pool significantly decreases with increasing rolling speed before the rolling speed reaches a critical value $(80 \mathrm{~mm} / \mathrm{s})$. At speeds higher than $80 \mathrm{~mm} / \mathrm{s}$, the water pool is in a stable state and the advancing/receding angle remains steady. In the case of the microgrooved surface, the influence of the microgroove on water lubricating flow disappears when the rolling speed reaches a critical value $(1030 \mathrm{~mm} / \mathrm{s})$.
\end{abstract}

Keywords: water lubrication; direct observation; point of contact

\section{Introduction}

The use of water lubrication in engineering can be traced back to about $2400 \mathrm{BC}$, when people used water as a lubricant in transporting statues in Egypt [1]. Water lubrication is widely used in a range of industrial application fields such as biomedical devices, rail/wheels and microelectromechanical systems [2-4].

The low cost, environmental friendliness, and the excellent cooling effect of water have attracted many researchers to investigate the tribological performance of different materials under water lubrication [5-13]. Lei et al. evaluated the tribological behavior of micro and nano-crystalline diamond films in water lubricating conditions [5]. Gao et al. investigated the tribological behaviors of epoxy composites under water lubrication conditions at both varying and constant sliding speeds [6]. Dong et al. studied the stick-slip behaviors of ultra-high molecular weight polyethylene, synthetic rubber and fiber resin composite polymer materials with $\mathrm{ZCuSn}_{10} \mathrm{Zn}_{2}$ plates under water-lubricated conditions [7]. Ma et al. studied the friction between a 440C stainless steel ball and a 440C stainless steel plate in water lubrication [8]. Niu et al. studied the friction and wear properties of titanium alloys against tungsten carbide under water-lubricated conditions using a ball-on-flat sliding friction apparatus [9]. Mamada et al. [10] systematically studied the friction properties of polyvinyl alcohol-hydrogel(PVA-H)/steel ball contact under water lubrication conditions. Wang et al. [11-13] comparatively investigated the tribological behaviors of several polymers under the lubrication of sea water. Liu et al. [14-18] systematically studied the forming characteristics of lubricating water films. In these systems, water in the contact region between two surfaces forms a lubrication film, which serves to prevent adhesion and wear and to reduce friction $[17,18]$. 
The properties of water confined in the contact region are very complex and have been studied in detail using experimental and simulative methods; e.g., atomic force microscopy $[19,20]$, interfacial force microscopy [21,22], surface force apparatus [2,3], numerical simulation [23] and molecular dynamic simulation $[24,25]$. However, there have been few studies reporting the direct observation of water flow behaviors in points of contact under water lubrication, which is a significant prerequisite for understanding the properties of flowing water. In this paper, there is an emphasis on the direct observation of the dynamic behaviors of lubricating water films. The results of this study help to improve the understanding of the behavior of lubricating films in water lubrication.

\section{Experimental Conditions}

In this work, the lubricating water film is formed between the surface of a $160 \mathrm{~mm}$ diameter glass disk and the surface of a 7/8 inch diameter steel ball. The steel ball used in our tests was swallowed partly in a water tank; the lubricating water comes from the water tank, and the water pool was formed by the rolling motion of the steel ball, as schematically shown in Figure 1. The glass disc coated with a semireflective chromium $(\mathrm{Cr})$ layer had a surface roughness $\mathrm{Ra}$ of approximately $0.5 \mathrm{~nm}$. The roughness of the surface of the highly-polished steel ball (AISI 52100) is around $3.7 \mathrm{~nm}$. The water would be entrained toward the contact region during the process of the glass disk being driven by a motor; the ball was driven by the disk, and can therefore be regarded as nominally pure rolling. The dynamic process during the rolling motion was recorded completely through the optically transparent glass disk using a digital camera. In addition, a light microscope was used to acquire the accurate localization of the contact region. The water level of the water tank was filled approximately halfway up the ball, as shown in Figure 1, so that the water as lubricant can be entrained into the contact region by the rolling motion of the ball. The load applied was $30 \mathrm{~N}$ corresponding to a maximum contact pressure of $0.53 \mathrm{GPa}$, which was calculated by Hertz's theory, and the test temperature was maintained at $25^{\circ} \mathrm{C}$ for all measurements. Water was distilled and deionized by using a milli-Q system (resistivity: $18 \mathrm{M} \Omega \cdot \mathrm{cm}$ ). All the parts, including the steel ball and glass disk, were all cleaned by ultrasonic cleaning in organic solvents before every set of tests.

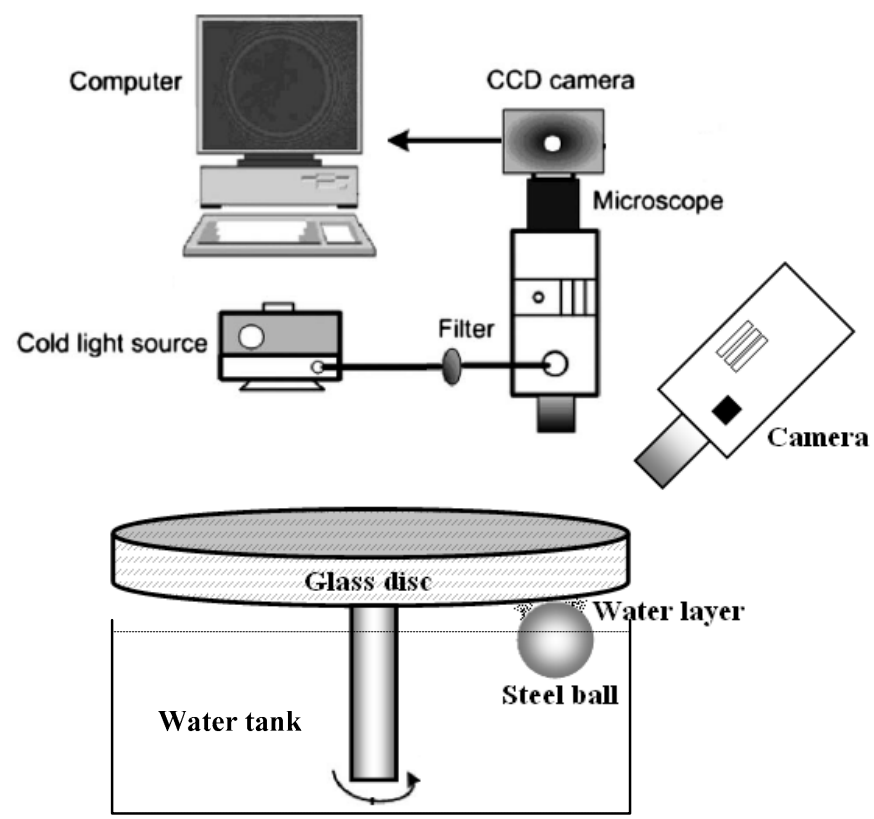

Figure 1. Schematic of test setup. The interfered light forms an image of monochromic interference fringes, recorded by a charge coupled device camera. The fluid of the water layer around the contact region is observed using another camera. 


\section{Results and Discussion}

\subsection{Observation on Water Flow between Smooth Surfaces}

The snapshots of de-ionized (DI) water film flowing between the steel ball and smooth disk under different rolling speeds from the camera are presented in Figure 2. The red arrow indicates the direction of liquid flow. The water layer in equilibrium state can be divided into three different regions, shown in Figure 2c. The region surrounded by the red dashed line is a water pool which surrounds the contact region. The low part of the water pool, indicated by two yellow dashed lines, is the inflow region, as shown in the $C$ region in Figure $2 c$. The $B$ region, surrounded by two green dashed lines, is the outflow region. The shape of the water pool is a manifestation of the flow characteristics. At a relatively low speed of $20 \mathrm{~mm} / \mathrm{s}$, the shape of the contact line between the water film and glass disc appears non-circular when the water is entrained into the area around the contact region (Figure 2a). When the speed is increased to $80 \mathrm{~mm} / \mathrm{s}$, the shape of the water film becomes elliptic, as shown in Figure 2c. The interference images of the water film near the contact region can be clearly observed in Figure 2a-1-c-1. The width of the outlet region becomes larger and the optical intensity of the central contact region decreases when the rolling speed increases. As a result, if the rolling speed increases, more water would be entrained into the contact region, forming a thicker film.

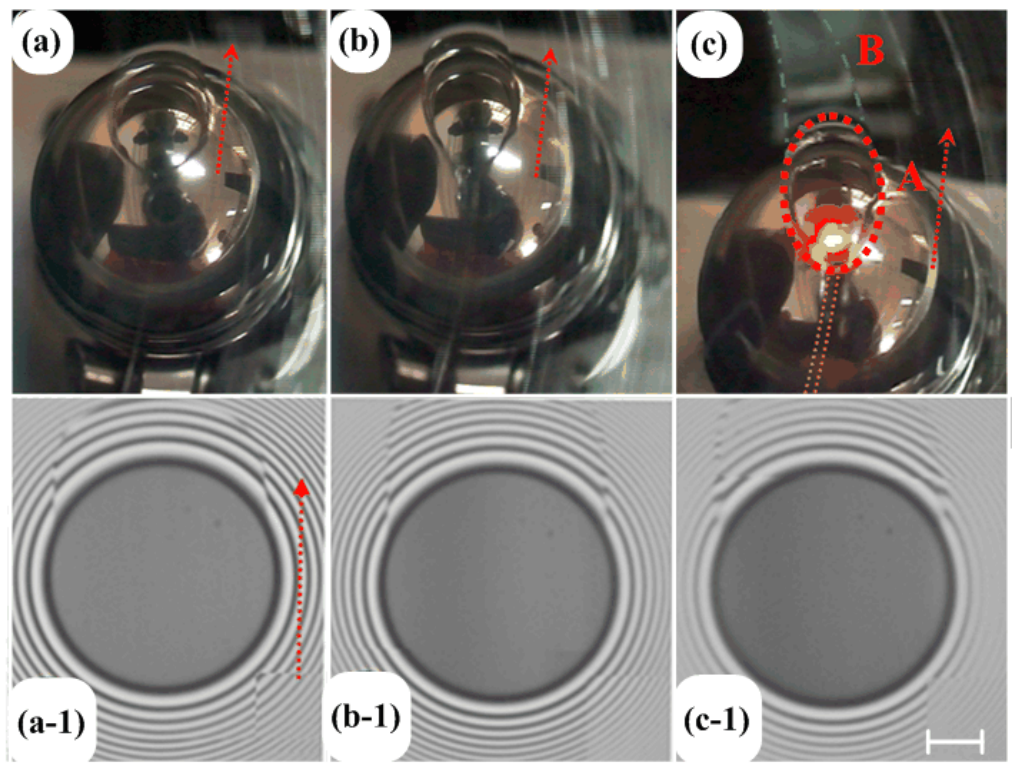

Figure 2. Typical photographic sequence (a-c) and interference patterns (a-1-c-1) of water flow between smooth surfaces at various speeds. The corresponding rolling speeds were as follows: (a) $20 \mathrm{~mm} / \mathrm{s}$; (b) $40 \mathrm{~mm} / \mathrm{s}$; (c) $80 \mathrm{~mm} / \mathrm{s}$. The dotted arrow symbol shows the direction of the rolling of the steel ball. Scale bar: $70 \mu \mathrm{m}$.

To investigate the effect of the rolling speed of the steel ball on the variation in the shape of the water pool, two parameters (advancing angle, $\theta_{\mathrm{A}}$, and receding angle, $\theta_{\mathrm{R}}$ ) were introduced as shown in Figure 3a. It should be noted that the red dashed line was indicative of the water pool. To quantitatively study the dynamic angle of the water pool, we extracted the shape of the water pool from the recorded images using standard image analysis techniques. The digital image shown in Figure $3 b$ was analyzed using Image $2 \times$ software (ImageJ $2 \times$, National Institutes of Health, Bethesda, MD, USA).

The advancing and receding angle of the snapshots were measured using Image $2 \times$ software to summarize the relationship between the dynamic angle and rolling speed, as shown in Figure 4 . The dynamic behaviors of the lubricating water film in the A region is characterized by an advancing 
angle, $\theta_{\mathrm{A}}\left({ }^{\circ}\right)$, of about 90,82 and 73 for a rolling speed of 0,40 and $80 \mathrm{~mm} / \mathrm{s}$, respectively. In phase A, the advancing angle was observed to be remarkably sensitive to the rolling speed and significantly decreased with increasing rolling speed. However, when the rolling speed was increased, the advancing angle did not change with rolling speed in phase B. The speed was named as the critical rolling speed $V c(\mathrm{~mm} / \mathrm{s})$. It is clear that the critical rolling speed was around $80 \mathrm{~mm} / \mathrm{s}$ under our working conditions. The variation of the receding angle, $\theta_{\mathrm{R}}\left({ }^{\circ}\right)$, is similar to that of the advancing contact angle, but the advancing contact angle is larger than the receding angle. The difference between the advancing and receding angles is known as angle hysteresis.
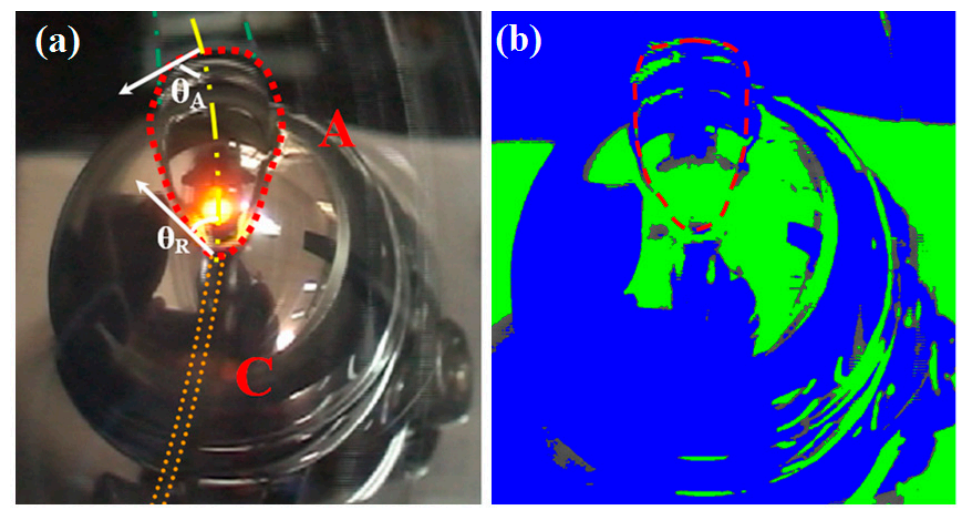

Figure 3. Water pool between smooth surfaces: (a) initial image; (b) colored digital image.

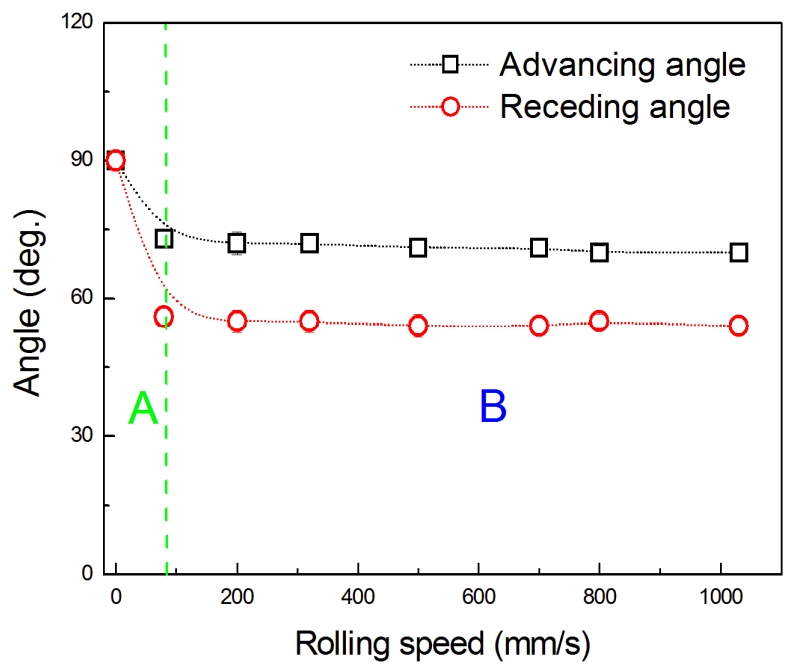

Figure 4. The effects of rolling speed on the dynamic angle of the water pool between smooth surfaces. In phase A, the advancing angle decreased with increasing rolling speed; In phase B, the advancing angle did not change with rolling speed.

When the steel ball and the glass disk are static, the total forces impacted on the water pool were symmetrical, resulting in the water pool being completely circular, as schematically shown in Figure 5 a. The total force $\vec{F}_{\text {tol-S }}(\mathrm{N})$ of the static water pool is listed below:

$$
\vec{F}_{\text {tol-S }}=G+\vec{F}_{N G}+\vec{F}_{N S}+\vec{r}_{w d}+\vec{r}_{w g}+\vec{r}_{w b}+\vec{P}_{0}
$$

where $G$ is the gravity (N), $\vec{F}_{N G}$ is the normal adhesion force (N) which is acting perpendicular to the interface between the water and the glass disk, $\vec{F}_{N S}$ is the normal adhesion force (N) which is acting perpendicular to the interface between the water and the steel ball, $\vec{r}_{w d}$ is the interfacial tension 
$(\mathrm{mN} / \mathrm{m})$ between the water and the disk, $\vec{r}_{\text {wg }}$ is the interfacial tension $(\mathrm{mN} / \mathrm{m})$ between the water and the gas, $\vec{r}_{w b}$ is the interfacial tension $(\mathrm{mN} / \mathrm{m})$ between the water and the ball, and $\vec{P}_{0}$ is the atmospheric pressure (Pa). The gravity $G$ is as follows,

$$
G=\iiint \rho g d v
$$

where $\rho$ is the water density $\left(\mathrm{kg} / \mathrm{m}^{3}\right), g$ is the acceleration of gravity $(\mathrm{N} / \mathrm{kg})$, and $d v$ is unit volume of the water pool.
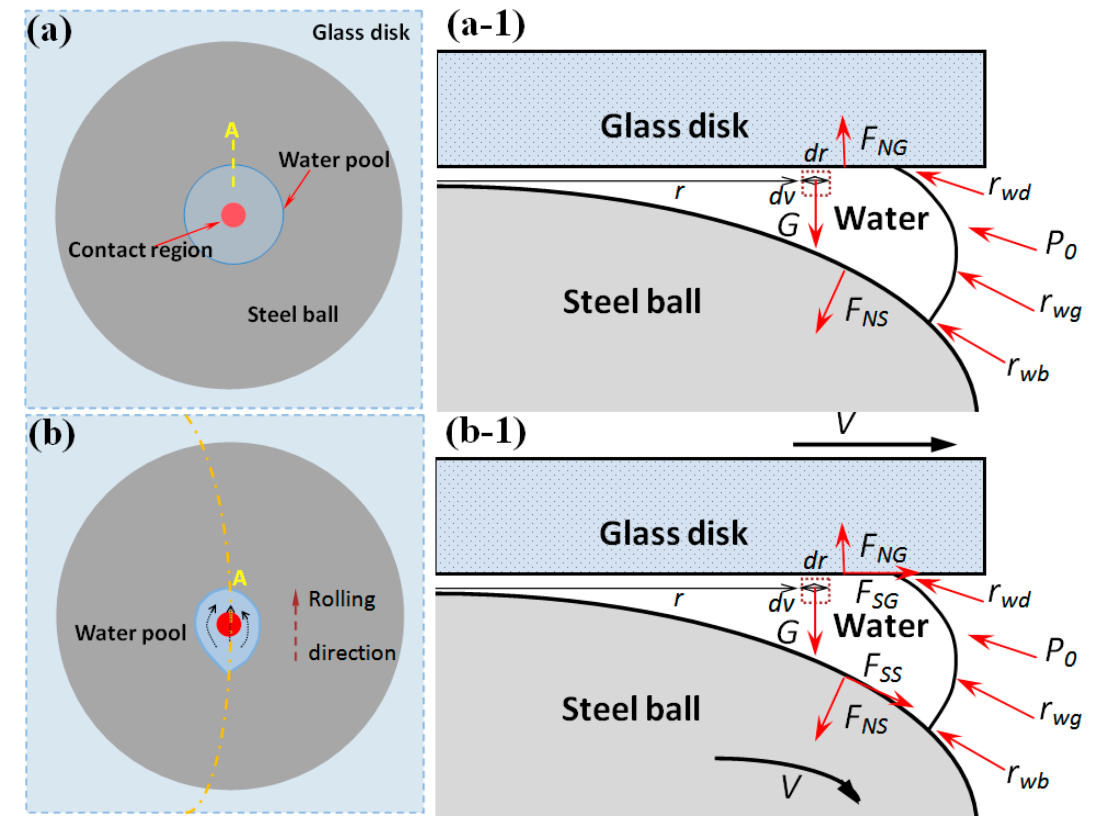

Figure 5. Left column: top view of the schematic diagram of the dynamic process of the water flow between smooth surfaces. Right column: side view of the schematic diagram of the force analysis. (a) Rolling speed was $0 \mathrm{~mm} / \mathrm{s}$; (a-1) Schematic diagram of the force analysis for Line A in the static water pool (corresponding to (a)); (b) Rolling speed was $80 \mathrm{~mm} / \mathrm{s}$; (b-1) Diagram of the force analysis for Line A in the static water pool (corresponding to $(\mathbf{b})$ ). the orange dashed line in $(\mathbf{b})$ indicated the rolling track.

As the rolling speeds of the steel ball and the glass disk were increased, the water entered the inlet region by means of the entrainment role. Some water went directly through the Hertzian contact region along the rolling direction, and the rest went through both sides of the contact region, as shown in Figure 5 b. The total force $\vec{F}_{\text {tol- }-M}$ of the motive water pool is as follows,

$$
\vec{F}_{\text {tol }-M}=G+\vec{F}_{N G}+\vec{F}_{N S}+\vec{F}_{S G}+\vec{F}_{S S}+\vec{r}_{w d}+\vec{r}_{w g}+\vec{r}_{w b}+\vec{P}_{0}
$$

where $\vec{F}_{S G}$ is the interfacial shear force (N) parallel to the interface of the water and the glass disk indicating the effect of the adhesion in the shear direction, and $\vec{F}_{S S}$ is the interfacial shear force (N) parallel to the interface between the water and the steel ball indicating the effect of the adhesion in the shear direction. The water flow played a shear role on the water pool, resulting in the fact that the water pool was elongated along the rolling direction and the advancing/receding angle significantly decreased with increasing rolling speed, as shown in Figure 4. When the rolling speed of the ball reaches a critical value $(80 \mathrm{~mm} / \mathrm{s})$, the water pool is in a stable state and the advancing/receding angle is a fixed value. 


\subsection{Observation on Water Flow between Microgrooved Surfaces}

After a smooth glass disk is worn by a steel ball, a microgroove is formed because of the worn $\mathrm{Cr}$ layer during the rolling motion in the contact region. The width of the surface microgroove is around $200 \mu \mathrm{m}$, as shown in Figure 6. Figure 7 shows a series of images recorded when water flows between the steel ball and the microgrooved disk. It is clearly seen that a heart-shaped contact line first appears in the A zone of Figure $7 \mathrm{a}$ and then is continuously elongated as rolling speed increased, as shown in Figure $7 \mathrm{~b}-\mathrm{d}$. When the rolling speed of the ball is $800 \mathrm{~mm} / \mathrm{s}$, the heart-shaped contact line disappears (Figure 7e). Finally, when the rolling speed is $1030 \mathrm{~mm} / \mathrm{s}$, the water layer around the contact region is divided into two regions, along with the artificial microgroove, as indicated by the yellow double-dotted dashed line (Figure 7f). It can be seen that the disturbed flow appears in the $\mathrm{G}$ region of Figure $7 f$. Figure 8 b,c shows the interference patterns of contact regions in Figure $7 \mathrm{e}, \mathrm{f}$. The interference patterns of the I and J region in Figure $7 \mathrm{~b}, \mathrm{c}$ are asymmetric. The interference patterns can be used to calculate the thickness of the water film in the contact region. Hence, the thickness distribution of water film in the contact region is asymmetric, which is attributed to the centrifugal effect of water film.

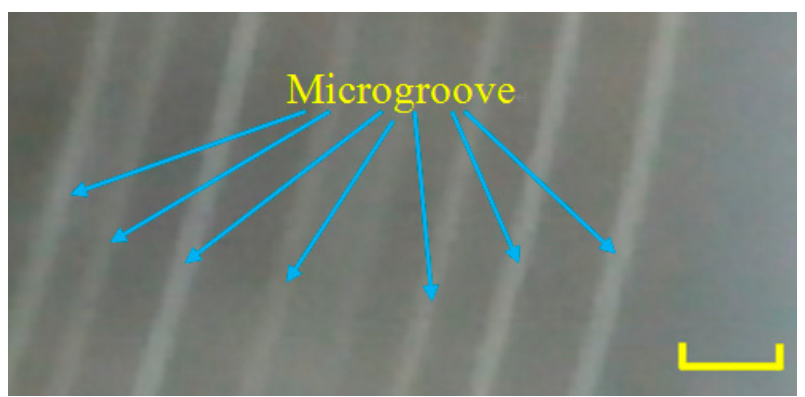

Figure 6. Typical photograph of the microgrooved surface on the glass disk. Scale bar: $800 \mu \mathrm{m}$.

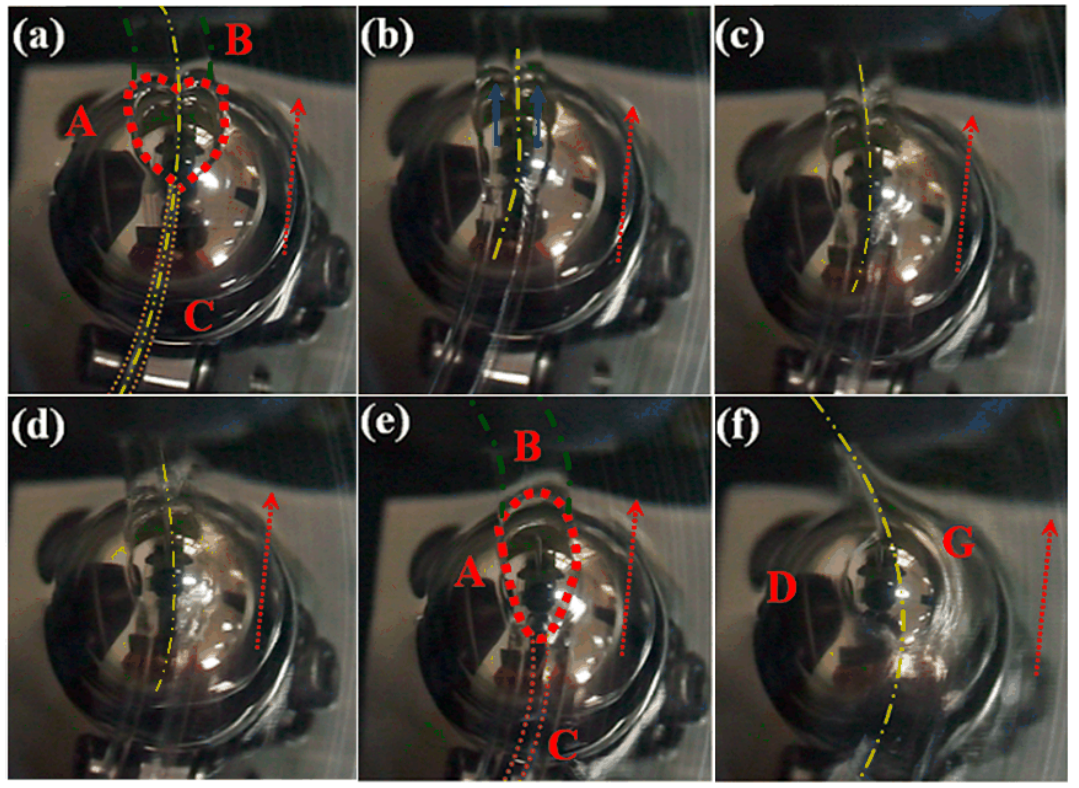

Figure 7. Typical photographic sequence of the water film flowing around the contact region on the microgrooved surface at various speeds: (a) $80 \mathrm{~mm} / \mathrm{s}$; (b) $200 \mathrm{~mm} / \mathrm{s}$; (c) $320 \mathrm{~mm} / \mathrm{s}$; (d) $700 \mathrm{~mm} / \mathrm{s}$; (e) $800 \mathrm{~mm} / \mathrm{s}$; (f) $1030 \mathrm{~mm} / \mathrm{s}$. The dotted arrow symbol shows the direction of the rolling of the steel ball. The solid arrow indicates the direction of water flow. The dashed line shows the direction the of microgroove. 

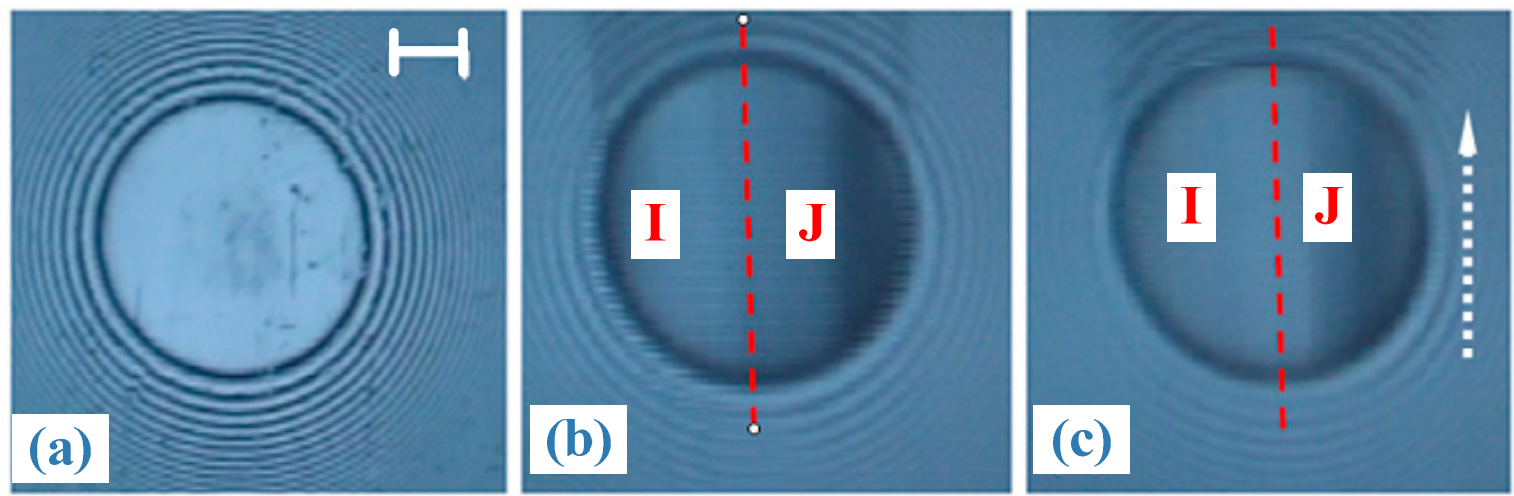

Figure 8. Interference patterns of water flow between microgrooved surfaces at various speeds: (a) $0 \mathrm{~mm} / \mathrm{s}$; (b) $800 \mathrm{~mm} / \mathrm{s}$; (c) $1030 \mathrm{~mm} / \mathrm{s}$. The dot arrow symbol shows the direction of the rolling of the steel ball. Scale bar: $70 \mu \mathrm{m}$.

In order to extract quantitative information, the advancing angle and receding angle from the snapshots in Figure $9 \mathrm{~b}$ were measured directly using ImageJ $2 \times$. The relationship between dynamic angle and rolling speed is summarized in Figure 10. These measurements reveal four distinct dynamic phases. In phase A (rolling speed $<200 \mathrm{~mm} / \mathrm{s}$ ), the receding angle was observed to be remarkably sensitive to the rolling speed and significantly decreased with increasing rolling speed, which is similar to that between the steel ball and smooth disk, shown in Figure 11b. However, the advancing angle significantly increased with rolling speed in phase $\mathrm{A}$, which is different to that between the steel ball and smooth disk, shown in Figure 11a. When the rolling speed of the ball ranges from 200 to $500 \mathrm{~mm} / \mathrm{s}$, as shown in phase $\mathrm{B}$, it behaves as showing a nearly constant angle (advancing angle: $137^{\circ}$; receding angle: $24^{\circ}$ ). When the rolling speed ranges from 500 to $800 \mathrm{~mm} / \mathrm{s}$, as shown in phase $\mathrm{C}$, the advancing angle was observed to be significantly decreased with increasing rolling speed, and the receding angle was a nearly constant angle. In phase $\mathrm{D}$, the advancing angle was a nearly constant angle and the receding angle was observed to be significantly increased with rolling speed. In phase $D$, the final values of the receding angle and advancing angle are similar between the microgrooved surface and smooth surface, shown in Figure 11.
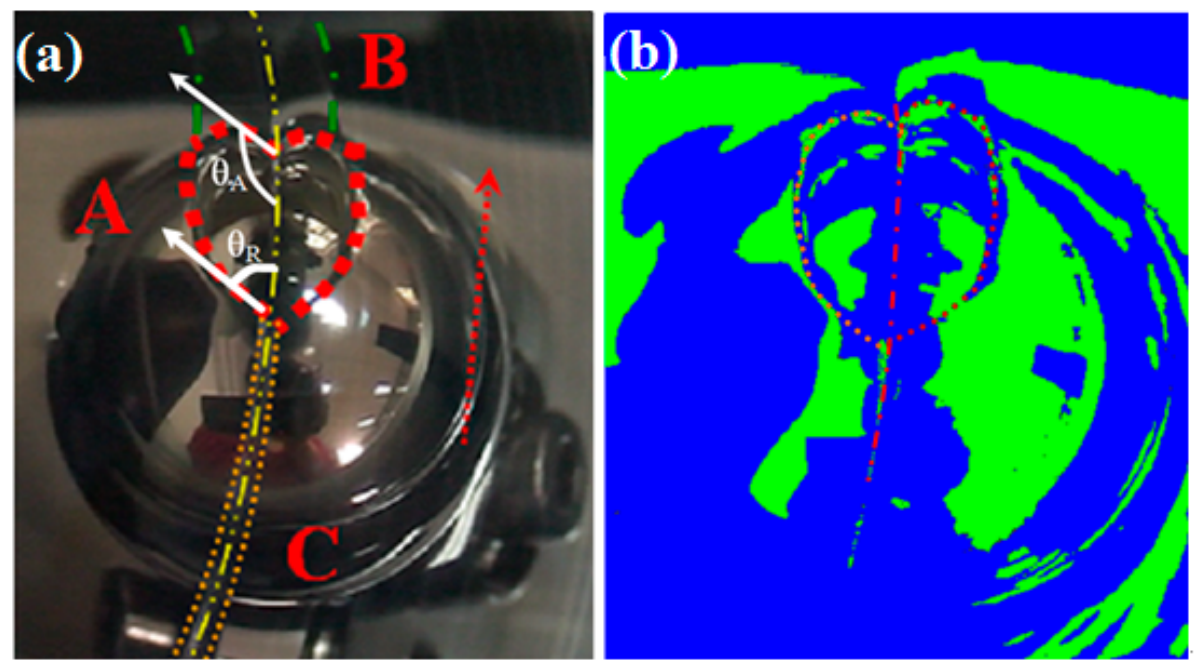

Figure 9. Water pool between microgrooved surfaces: (a) initial image; (b) colored digital image. 


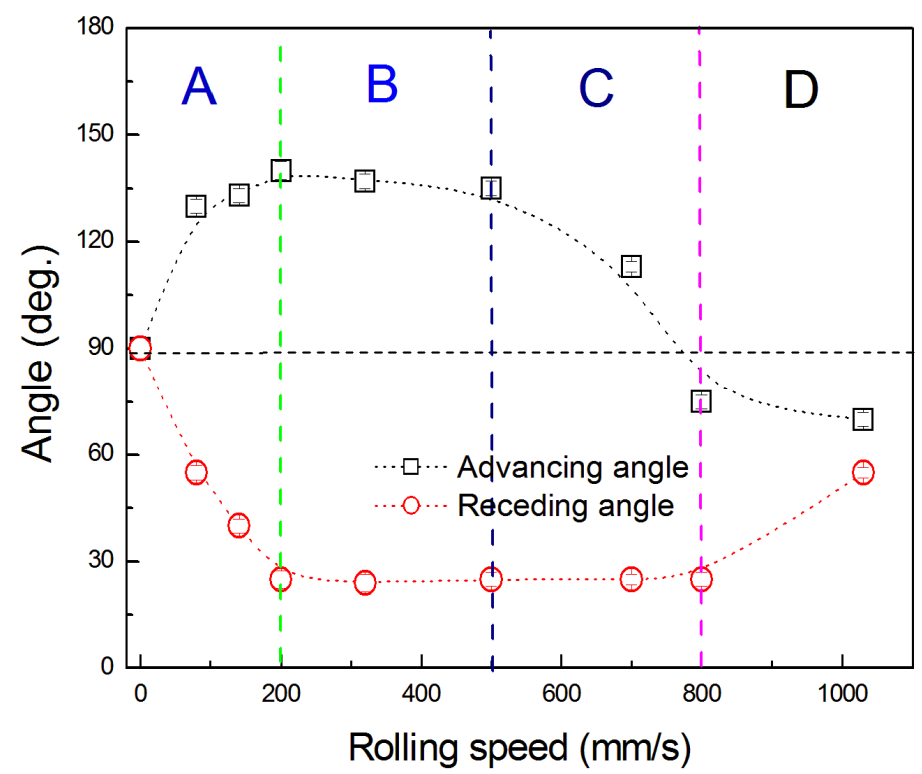

Figure 10. Effects of rolling speed on the dynamic angle of the water pool between microgrooved surfaces. In phase A, the receding angle decreased with increasing rolling speed, while the advancing angle significantly increased with increasing rolling speed; In phase $\mathrm{B}$, the two angles behaves as showing a nearly constant angle; In phase $C$, the advancing angle decreased with increasing rolling speed, while the receding angle was a nearly constant angle. In phase D, the advancing angle was a nearly constant angle, while the receding angle increased with rolling speed.
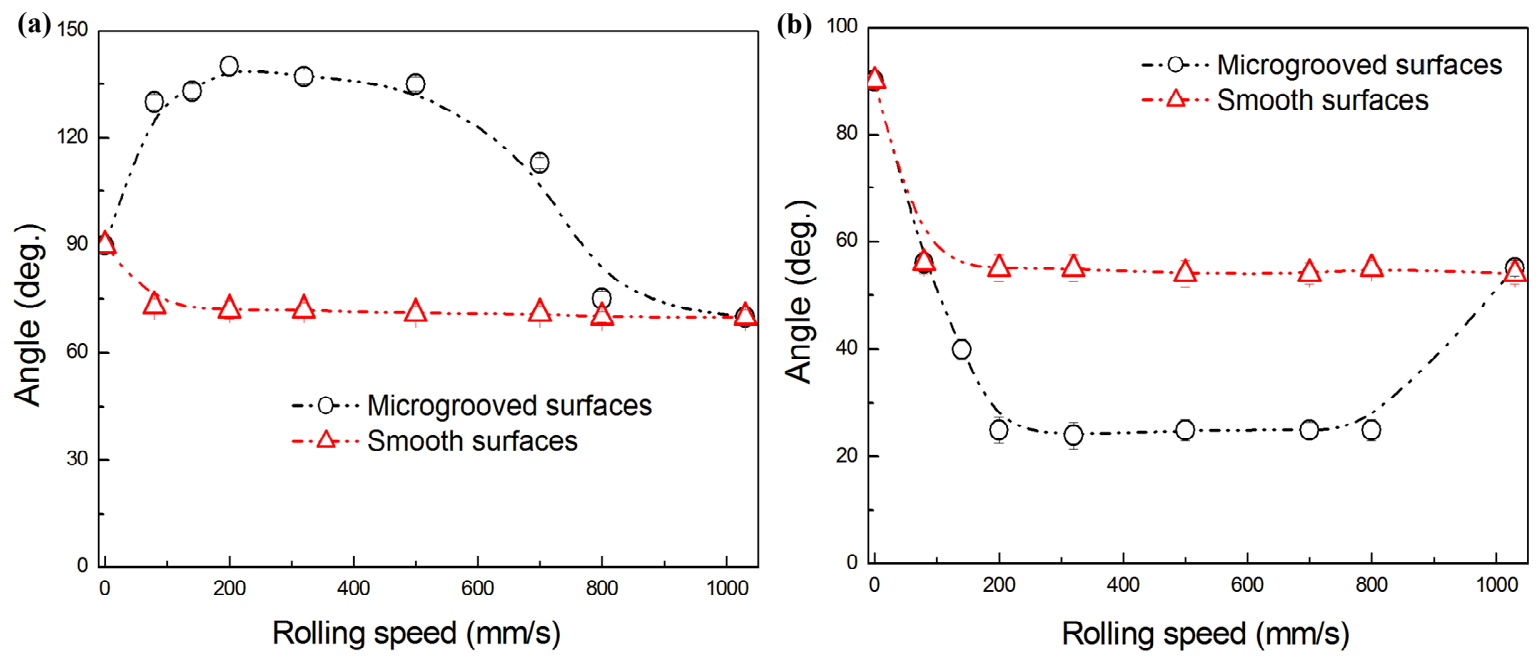

Figure 11. Effects of surface condition on the dynamic angle of the water pool: (a) Advancing angle; (b) receding angle.

From a mechanistic perspective, it is necessary to discuss some related theoretical issues. A force analysis of the dynamic process of the water flow between microgrooved surfaces was carried out, as schematically shown in Figure 12. The total force $\vec{F}_{\text {tol }-M-M}(\mathrm{~N})$ of the motive water pool between microgrooved surfaces is as follows,

$$
\vec{F}_{\text {tol-M-M }}=G+\vec{F}_{N G}+\vec{F}_{N S}+\vec{F}_{S G}+\vec{F}_{S S}+\vec{r}_{w d}+\vec{r}_{w g}+\vec{r}_{w b}+\vec{r}_{w m}+\vec{P}_{0}
$$

where $\vec{r}_{w m}$ is the interfacial tension $(\mathrm{mN} / \mathrm{m})$ between the water and the microgroove. When the rolling speed is $<500 \mathrm{~mm} / \mathrm{s}$, the interfacial tension between the water and the microgroove restrains the motion 
of water flow around the microgroove, so that a heart-shaped contact line appears in Figure 7a-d. When the rolling speed is $>500 \mathrm{~mm} / \mathrm{s}$, the kinetic energy of water flow around the microgroove is enhanced, and the influence of interfacial tension between the water and the microgroove weakens. Finally, the influence of the microgroove on lubricating water flow disappears when the rolling speed is $1030 \mathrm{~mm} / \mathrm{s}$.
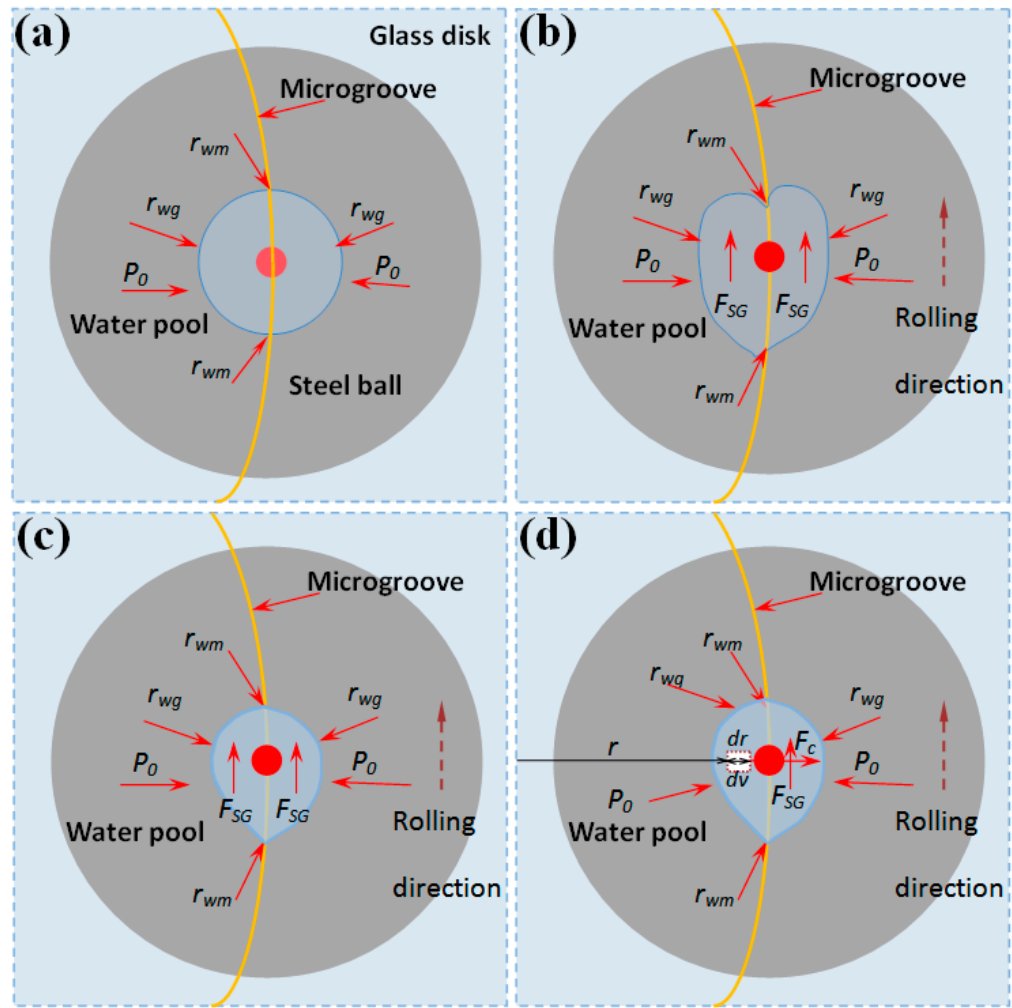

Figure 12. Top view of the schematic diagram of the dynamic process of the water flow between microgrooved surfaces. (a) Contact area between the water pool and microgroove under point of contact; $(\mathbf{b}, \mathbf{c})$ the force analysis of the motive water pool during rolling; (d) the total force of the motive water pool between microgrooved surfaces.

\section{Conclusions}

In this study, the behavior of a pool of water lubricating under a point of contact between a glass disk and a steel ball is investigated. A deformed water pool was found to form around the contact region under different rolling speeds. Two angles (advancing angle and receding angle) were introduced to investigate the effect of the rolling speed on the variation in the shape of the water pool. Two kinds of glass surfaces (smooth surface and microgrooved surface) were observed. In the case of the smooth surface, the advancing/receding angle significantly decreased with increasing rolling speed before the rolling speed reached a critical value,the water pool was in a stable state, and the advancing/receding angle was a fixed value after the rolling speed reached the critical value. In the case of the microgrooved surface, the influence of the microgroove on lubricating water flow disappeared when the rolling speed reached a critical value. Additionally, there are four distinct dynamic phases summarized from the relationship between the dynamic angle and rolling speed between the water pool and microgrooved surfaces under the point of contact. The current result emphasizes the direct observation, and could further our understanding of water lubrication behavior, such as the starvation in the inlet region and the subsequent occurrence of lubrication failure in the application of water-based lubrication of bearings. 
Acknowledgments: Support by National Natural Science Foundation of China (No. 51575529) and Science Foundation of China University of Petroleum, Beijing (No. 2462015YQ0401).

Author Contributions: Hang Zhang wrote the manuscript, Huaping Xiao conducted the experiments, Shu-Hai Liu designed the input structures and analyzed the data.

Conflicts of Interest: The authors declare no conflict of interest.

\section{References}

1. Dowson, D. History of Tribology; Longman: London, UK, 1979.

2. Özmen, Y. Si3N4 as a biomaterial and its tribo-characterization under water lubrication. Lubr. Sci. 2016, 28, 243-254. [CrossRef]

3. Cyriac, F.; Lugt, P.M.; Bosman, R. Impact of water on the rheology of lubricating greases. Tribol. Trans. 2016, 59, 679-689. [CrossRef]

4. Huang, W.; Cao, X.; Wen, Z. A Subscale Experimental Investigation on the Influence of Sanding on Adhesion and Rolling Contact Fatigue of Wheel/Rail Under Water Condition. J. Tribol. 2017, 139, 011401. [CrossRef]

5. Lei, X.; Shen, B.; Chen, S. Tribological behavior between micro-and nano-crystalline diamond films under dry sliding and water lubrication. Tribol. Int. 2014, 69, 118-127. [CrossRef]

6. Gao, C.P.; Guo, G.F.; Zhao, F.Y. Tribological behaviors of epoxy composites under water lubrication conditions. Tribol. Int. 2016, 95, 333-341. [CrossRef]

7. Dong, C.; Shi, L.; Li, L.; Bai, X.; Yuan, C.; Tian, Y. Stick-slip behaviours of water lubrication polymer materials under low speed conditions. Tribol. Int. 2017, 106, 55-61. [CrossRef]

8. Ma, Q.; Zhou, F.; Gao, S. Influence of boron content on the microstructure and tribological properties of Cr-BN coatings in water lubrication. Appl. Surf. Sci. 2016, 377, 394-405. [CrossRef]

9. Niu, Q.L.; Zheng, X.H.; Ming, W.W. Friction and wear performance of titanium alloys against tungsten carbide under dry sliding and water lubrication. Tribol. Trans. 2013, 56, 101-108. [CrossRef]

10. Mamada, K.; Kosukegawa, H.; Fridrici, V. Friction properties of PVA-H/steel ball contact under water lubrication conditions. Tribol. Int. 2011, 44, 757-763. [CrossRef]

11. Wang, J.; Yan, F.; Xue, Q. Friction and wear behavior of ultra-high molecular weight polyethylene sliding against GCr15 steel and electroless Ni-P alloy coating under the lubrication of seawater. Tribol. Lett. 2009, 35, 85-95. [CrossRef]

12. Chen, B.; Wang, J.; Yan, F. Friction and wear behaviors of several polymers sliding against GCr15 and 316 steel under the lubrication of sea water. Tribol. Lett. 2011, 42, 17-25. [CrossRef]

13. Chen, B.; Wang, J.; Yan, F. Comparative investigation on the tribological behaviors of CF/PEEK composites under sea water lubrication. Tribol. Int. 2012, 52, 170-177. [CrossRef]

14. Liu, S.H.; Luo, J.B.; Li, G.; Zhang, C.H.; Lu, X.C. Effect of surface physicochemical properties on the lubricating properties of water film. Appl. Surf. Sci. 2008, 254, 7137-7142. [CrossRef]

15. Liu, S.H.; Luo, J.B.; Xie, G.X.; Guo, D. Effect of surface charge on water film nanoconfined between hydrophilic solid surfaces. J. Appl. Phys. 2009, 105, 124301. [CrossRef]

16. Liu, S.H.; Guo, D.; Xie, G.X. Water film confined in a nanoscale gap: Surface polarity and hydration effects. J. Appl. Phys. 2010, 108, 084315. [CrossRef]

17. Jahanmir, S.; Ozmen, Y.; Ives, L.K. Water lubrication of silicon nitride in sliding. Tribol. Lett. 2004, 17, 409-417. [CrossRef]

18. Briscoe, W.H.; Titmuss, S.; Tiberg, F. Boundary lubrication under water. Nature 2006, 444, 191-194. [CrossRef] [PubMed]

19. Hu, J.; Xiao, X.D.; Ogletree, D.F. Imaging the condensation and evaporation of molecularly thin films of water with nanometer resolution. Science 1995, 268, 267-269. [CrossRef] [PubMed]

20. Gao, J.; Szoszkiewicz, R.; Landman, U. Structured and viscous water in subnanometer gaps. Phys. Rev. B 2007, 75, 115415.

21. Major, R.C.; Houston, J.E.; McGrath, M.J. Viscous water meniscus under nanoconfinement. Phys. Rev. Lett. 2006, 96, 177803. [CrossRef] [PubMed]

22. Goertz, M.P.; Houston, J.E.; Zhu, X.Y. Hydrophilicity and the viscosity of interfacial water. Langmuir 2007, 23, 5491-5497. [CrossRef] [PubMed] 
23. Wong, P.L.; Huang, P.; Meng, Y. The effect of the electric double layer on a very thin water lubricating film. Tribol. Lett. 2003, 14, 197-203. [CrossRef]

24. Leng, Y.; Cummings, P.T. Fluidity of hydration layers nanoconfined between mica surfaces. Phys. Rev. Lett. 2005, 94, 026101. [CrossRef] [PubMed]

25. Lane, J.M.D.; Chandross, M.; Stevens, M.J. Water in nanoconfinement between hydrophilic self-assembled monolayers. Langmuir 2008, 24, 5209-5212. [CrossRef] [PubMed]

(c) (1) 